\title{
Õpetaja ja sotsiaalpedagoog kui kiusamise ohvrid
}

\author{
Kristi Kõiv ${ }^{\mathrm{a}^{1}}$ \\ ${ }^{a}$ Tartu Ülikooli haridusteaduste instituut
}

\begin{abstract}
Annotatsioon
Uurimuse eesmärk on võrrelda õpetajate ja sotsiaalpedagoogide ohvrikäitumise levimust ja olemust seoses õpilaste- ja täiskasvanutepoolse (õpetajate, juhtkonna, lapsevanemate, teiste koolitöötajate) kiusamisega Eestis. Üleriigilisest läbilõikeuuringust, mille käigus vastasid enesekohasele ankeedile 564 õpetajat ja 153 sotsiaalpedagoogi, ilmneb, et õpetajate seas oli ulatuslikumalt levinud õpilastepoolne kiusamine ja sotsiaalpedagoogide seas täiskasvanutevaheline kiusamine. Kinnitust leiab püstitatud hüpotees, et õpetajate puhul on õpilaste ja lapsevanemate verbaalne kiusamine ohuna personaalsele positsioonile ulatuslikum kui sotsiaalpedagoogidel. Lisaks selgub uurimistulemustest, et õpetajad on kogenud õpetajate- ja juhtkonnapoolse kiusamise liikidest sagedamini füüsilist isolatsiooni ning sotsiaalpedagoogid lapsevanematepoolse ja teiste koolitöötajate poolse kiusamise liikidest info varjamist. Uuritavate ohvrikäitumise levimust kiusamiskategooriate ja -liikide kaupa interpreteeritakse varasemate uuringute taustal.
\end{abstract}

Võtmesõnad: kiusamine, ohvrikäitumise ulatus, õpetaja, sotsiaalpedagoog, Eesti

\section{Sissejuhatus}

Teadusuuringud kiusamise vallas on saanud laialdase rahvusvahelise mõõtme kooli kontekstis (nt Smith et al., 1999), kusjuures valdkond on laienenud ning rikastunud uurimuste ja teoreetiliste lähenemisviisidega teistest kontekstidest, nt hoolekandeasutused, kodu, noorte käimissuhted, vangla, kiusamine tööl (Monks \& Coyne, 2011). Enamikus koolikiusamist (Smith, 2011) ja töökiusamist (Coyne, 2011) käsitlevates uurimustes defineeritakse kiusamist kolme kriteeriumi alusel: keegi teeb teisele tahtlikult kahju või haiget; agressioon kordub 
pika perioodi vältel; eksisteerib tasakaalutus võimusuhetes, nii et inimene, kes on kiusamise ohver, ei saa ennast kaitsta või tal on raske seda teha.

Kiusamist eri kontekstides käsitletakse kogu maailmas (ja ka Eestis) peamiselt koolikiusamise aspektist, vaadeldes kiusamist õpilaste vahel (Kõiv, 2009; Monks et al., 2009). Kuid kiusamine hõlmab ka töökiusamist, mis haarab enda alla täiskasvanutevahelise kiusamise (Edelmann \& Woodall, 1997), kätkedes ka ohvri kogemuse ja tajutud kahju, mida agressor ohvrile põhjustab (Rayner \& Keashly, 2005). Töökiusamine võib olla otseselt tööga seotud (nt üle jõu käivad või töökohustuste hulka mittekuuluvad tööülesanded), kuid see võib seisneda ka ohus tööalasele staatusele (nt arvamuste halvustamine, süüdistused seoses jõupingutuste puudumisega) ja personaalsele positsioonile (nt hirmutamine, solvamine) ning isolatsioonis (Rayner \& Hoel, 1997).

Kiusamine kooli kontekstis on dünaamiliselt keeruline protsess (Parsons, 2005), sest ka õpetajad võivad olla nii õpilaste kui ka teiste õpetajate, juhtkonna, lapsevanemate ja teiste koolitöötajate (nt mittepedagoogilise personali, teiste spetsialistide) kiusamiskäitumise ohvrid, kuid nad võivad olla ka agressori rollis (nt õpetajatepoolne õpilaste kiusamine, vt Delfabbro et al., 2006; Twemlow \& Fonagy, 2005; Whitted \& Dupper, 2008).

\section{Õpetaja kui töökiusamise ohver}

Õpetajate langemist kiusamise ohvriks (edaspidi: ohvrikäitumine) käsitlevad uurimused on alguse saanud ligi kaks kümnendit tagasi, kui Pervin ja Turner (1998) hakkasid uurima õpilastepoolset õpetajate kiusamist. Viimase kümnendi jooksul on uurimuste käsitlusala rahvusvaheliselt laienenud ning õpetajat on hakatud vaatlema töökiusamise ohvrina. Enesekohaseid küsimustikke kasutades on uuritud, kuivõrd levinud on õpetaja langemine töökiusamise ohvriks. Uurimistulemustest ilmneb, et Austraalias oli 99\% õpetajatest kokku puutunud mõne ohvrikäitumise liigiga (Riley, Duncan, \& Edwards, 2011), Ameerika Ühendriikides oli 80\% õpetajatest kogenud ohvrikäitumist (McMahon et al., 2014), Hispaanias oli ligi viiendik õpetajatest koos teiste elukutsete esindajatega kogenud kiusamist (Jennifer, Cowei, \& Ananiadou, 2003), Horvaatias oli 22\% õpetajatest kogenud kiusamist ja 32\% näinud kiusamist pealt (Russo, Milić, Knežević, Mulić, \& Mustajbegović, 2008), Eestis oli ligikaudu kolmandik õpetajatest olnud korduva kiusamise ohver (Kõiv, 2011), Leedus oli üle neljandiku õpetajatest kogenud kiusamist (Malinauskienë, Obelenis, \& Đopagienë, 2005), Lõuna-Aafrikas oli ligi 90\% õpetajatest kogenud kiusamist ja neljandik regulaarselt ohvriks langenud (De Wet \& Jacobs, 2013), Soomes oli 9\% õpetajatest kogenud sagedat tõsist kiusamist (Pyhältö, Pietarinen, \& Soini, 2015), Türgis oli ligikaudu 50\% õpetajatest kogenud ohvrikäitumist (Cemaloğlu, 2007), 
Uus-Meremaal oli 40\% õpetajatest kogenud kiusamist (Benefield, 2004) ning Ühendkuningriigis oli $62 \%$ õpetajatest kogenud või pealt näinud töökohal kiusamist (NASUWT, 2012). Ariza-Montes jt (2016) osutavad, et uuringu kohaselt oli Euroopa Liidu ja teistes riikides (nt Türgi, Norra, Makedoonia, Montenegro, Albaania) 49\% kõigi õpetamisega seotud elukutsete esindajatest, sh ülikoolide õppejõud, kutsekoolide, üldhariduskoolide ja koolieelsete lasteasutuste õpetajad, kogenud töökiusamist. Rahvusvahelistest uurimustest aga ilmneb, et õpetajate töökiusamise levimus varieerub, sõltudes kasutatud metoodikast, sest osas uurimustes arvestatakse ja osas ei arvestata probleemi korduvust ja/või tõsidust. See tekitab vajaduse uuringuid selles vallas jätkata, sest õpetajate kiusamise levimus tööl on viimasel aastakümnendil näidanud tõusutendentsi (Kõiv, 2015; NASUWT, 2012).

\section{Õpetaja kui õpilastepoolse kiusamise ohver}

Õpilastepoolse õpetajate kiusamise korral on laps agressor ja täiskasvanu ohver, kusjuures agressiivset käitumist iseloomustab kolm keskset tunnusjoont: tahtlikkus, korduvus ja võimusuhete tasakaalutus. Just võimusuhete tasakaalutus on tunnus, mille poolest erineb õpilastepoolne õpetaja kiusamine koolikiusamisest õpilaste vahel ja töökiusamisest - tegu on tavalise staatusest tuleneva positsiooni ümberpööramisega kooli kontekstis (Terry, 1998). Metoodiliselt on varasemad uuringud selles vallas kahesugused: uuritud on õpilastepoolset õpetajate kiusamist õpilaste hinnangute (nt James et al., 2008; Khoury-Kassabri, Astor, \& Benbenishty, 2009) ja õpetajate hinnangute alusel.

Õpetajate ohvrikäitumise levimuse ja olemuse kvantitatiivsed uuringud, milles kasutatakse enesekohaseid küsimustikke, on kasvava huvi objektiks eri maades, eriti võrdluses kvalitatiivsete uuringutega õpilastepoolse õpetajate kiusamise kohta (nt De Wet, 2010b, 2012). Näiteks selgub Soomes tehtud uuringust (Kauppi \& Pörhölä, 2012), et ligikaudu veerand õpetajatest oli kogenud õpilastepoolset kiusamist aeg-ajalt, 3\% sageli ja 4\% peaaegu iga päev ning et õpetajate kogemused õpilastepoolse kiusamisega olid seotud eelkõige otseste (nt solvamine, hirmutamine), kuid ka kaudset laadi professionaalseid oskusi (nt koostööst keeldumine, ignoreerimine) puudutavate kiusamisliikidega. Eestis korraldatud uuring (Kõiv, 2011) näitab, et viiendik õpetajatest oli kogenud õpilastepoolset kiusamist, mille puhul olid sagedasimad verbaalse kiusamise liigid (karjumine, põhjendamatud nõudmised, solvamine). Lõuna-Ameerikas tehtud uuringust (De Wet, 2006) selgub, et kolmandikul juhtudest olid õpetajad kogenud õpilastepoolset kaudset verbaalset kiusamist ja neljandikul juhtudest füüsilist otsest kiusamist. Ka Terry (1998) uuring Ühendkuningriigis näitab, et üle poolte õpetajatest oli kogenud õpilastepoolset kiusamist, 
millest sagedasimateks liikideks olid allumatus, hüüdnimedega nimetamine, mittekooperatiivsus, isiklike asjade äravõtmine ja ähvardamine vägivallaga. Slovakkias korraldatud uuring (Dzuka \& Dalbert, 2007) viitab, et ligi pooltel õpetajatest oli õpilastepoolse kiusamise kogemus, mis kolmandikul juhtudest seostus verbaalse vägivallaga, $12 \%$ isiklike asjade lõhkumisega ja 5\% füüsilise vägivallaga. Türgis tehtud uuringu (Özkiliç, 2012) alusel oli ligi 40\% õpetajatel õpilastepoolse kiusamise kogemus, kusjuures rohkem kui kolmandikul oli see verbaalset laadi, kolmandikul ignoreerimine, neljandikul alusetud kuulujutud ja vähematel juhtudel (18\%) füüsiline agressioon. Niisiis, eri maades korraldatud kvantitatiivsete uuringute kontekstis ilmneb, et viiendikul kuni pooltel juhtudest on õpetajat vaadeldud õpilastepoolse kiusamise ohvrina, kuid leiduvad vaid mõned kvalitatiivsed (Lõuna-Aafrika: De Wet, 2010a; 2011) ja kvantitatiivsed (Ameerika Ühendriigid: Blasé, Blasé, \& Du, 2008) uuringud, kus õpetajat on vaadeldud kooli juhtkonna poolse kiusamise ohvrina.

\section{Õpetaja kui mitmepoolse kiusamise ohver}

Õpetajad kui mitmepoolse kiusamise ohvrid on olnud keskmeks mitmes uuringus, kus õpetajate ohvrikäitumise levimuse hindamisel on kasutatud enesekohaseid küsimustikke. Benefieldi (2004) uurimistulemused osutavad, et Uus-Meremaa õpetajad kogesid eelkõige õpilastepoolset kiusamist, kuid kiusajaks oli ka juhtkond, samuti vanemad ja teised õpetajad. Ka Eestis tehtud uuringu (Kõiv, 2011) tulemused näitavad õpilastepoolse kiusamise prevaleerimist õpetajate seas võrreldes täiskasvanutepoolse kiusamisega koolis. Ameerika Ühendriikides korraldatud uuringust (McMahon et al., 2014) aga nähtub, et 37\% juhtudel kiusasid õpetajaid õpilased, 21\% juhtudel teised õpetajad ning 9\% juhtudel teised koolitöötajad. Ent Ühendkuningriigi uuringu (NASUWT, 2012) andmed näitavad eelkõige juhtkonna kiusamiskäitumise ülekaalu (üle 60\% juhtudel), seevastu õpetajate ja teiste koolitöötajate kiusamiskäitumine on väiksema kaaluga (vastavalt 7\% ja 5\% juhtudel). Iirimaal tehtud uuringu (McGuckin \& Lewis, 2008) kohaselt oli 42\% õpetajatest kogenud lapsevanematepoolset kiusamist, 20\% õpilastepoolset kiusamist, 19\% teiste õpetajate poolset kiusamist ning $12 \%$ nii õpilaste- kui ka lapsevanematepoolset kiusamist.

Uuringute andmed viitavad, et õpetaja on ühe- või mitmepoolse kiusamise ohvrina kogenud ohvrikäitumise liikidest kõige sagedamini õpilastepoolset kiusamist (Bradshaw, Waasdorp, O'Brennan, \& Gulemetova, 2013; De Wet, 2010b; Dzuka \& Dalbert, 2007; James et al., 2008; Kauppi \& Pörhölä, 2012; Pervin \& Turner, 1998; Terry, 1998; Özkiliç, 2012) ja erinevate täiskasvanute poolset kiusamist (Benefield, 2004; Kõiv, 2011, 2015; McMahon et al., 2014; NASUWT, 2012), mis on seotud verbaalsete ähvardustega ning ohustanud 
õpetaja personaalset positsiooni ja professionaalset staatust. Lisaks võib välja tuua, et Ameerika Ühendriikide õpetajate ja ka teiste koolitöötajate seas korraldatud küsitluse andmete põhjal olid õpetajad verbaalset ja suhetega seotud kaudset kiusamist kogenud sagedamini kui teised koolitöötajad (Bradshaw et al., 2013). Samast uuringust ilmnes, et agressorid olid nii ópetajate kui ka teiste koolitöötajate hinnangul sarnased: kõige enam nimetati agressorina õpetajaid, seejärel juhtkonda ja suhteliselt vähem lapsevanemaid (ibid.).

Seega, haridusvaldkonna rahvusvahelistes uurimustes on õpetajate ohvrikäitumise levimuse ja olemuse uurimisel keskendutud kahe kümnendi jooksul õpetajale kui ühe- või mitmepoolse kiusamise ohvrile, kuid autorile teadaolevalt leiduvad vaid mõned sama temaatikat puudutavad uurimused sotsiaalvaldkonnast sotsiaaltöötajate kui abistava elukutse esindajate kohta. Ameerika Ühendriikide sotsiaaltöötajate seas tehtud uuringust (Whitaker, 2012) selgub, et kiusamisliikidest olid ülekaalukad verbaalsed vaenulikud aktid ning kiusajateks oli 49\% juhtudel juhtkond, 30\% juhtudel kolleegid ja 12\% juhtudel kliendid. Ka van Heugteni (2010) uuring näitab, et sotsiaaltöötajad pidasid kiusajatena töökohal silmas eelkõige juhte ja juhtkonda.

Praeguse uurimuse eesmärk on võrrelda õpetajate ja sotsiaalpedagoogide ohvrikäitumise levimust ning olemust seoses õpilaste- ja täiskasvanutepoolse kiusamisega. Eesmärgist lähtudes on sõnastatud kaks uurimisküsimust.

1. Milline on õpetajate ja sotsiaalpedagoogide õpilaste- ja täiskasvanutepoolse (õpetajate, juhtkonna, lapsevanemate, teiste koolitöötajate) kiusamise levimus ohvrikäitumise liikide kaupa?

2. Milline on õpetajate ja sotsiaalpedagoogide õpilaste- ja täiskasvanutepoolse kiusamise levimus kiusamiskategooriate kaupa (oht professionaalsele staatusele, oht personaalsele positsioonile, isolatsioon, füüsiline agressioon)?

Püstitati hüpotees, et õpetajatel on ópilaste- ja lapsevanematepoolne kiusamine, mille korral verbaalselt ohustatakse personaalset positsiooni, ulatuslikum kui sotsiaalpedagoogidel.

\section{Meetod}

\section{Uuringu disain ja uuritavad}

Läbilõikeuuringus kasutati kahe üleriigilise valimi moodustamiseks eri strateegiaid. Kõigist maakondadest valiti süstemaatilise juhuvaliku teel välja kaks kooli nii, et põhikoolide ja gümnaasiumide suhtarv vastaks üleriigilisele valimile, ning 2016. aastal saadeti kõigi valimisse kuulunud koolide õpetajatele anonüümsed ja konfidentsiaalsed e-küsimustikud. Vastanute protsent oli 54,7. Kokku kuulus esimesse valimisse 567 õpetajat, kellest 502 (88,5\%) olid naised 
ja $65(11,5 \%)$ mehed. Õpetajate keskmine vanus oli 46,2 aastat $(S D=11,7)$, kusjuures noorim osaleja oli 20aastane ja vanim 71aastane.

Kõigile sotsiaalpedagoogidele, kes töötasid $90 \%$ juhtudel koolides, saadeti 2016. aastal e-küsimustikud, millele vastas $58,8 \%$ koguvalimist. Kokku kuulus teise valimisse 153 sotsiaalpedagoogi, kellest 147 (95,4\%) olid naised ja $7(4,6 \%)$ mehed. Vastajate keskmine vanus oli 41,3 aastat $(S D=8,5)$, kusjuures noorim osaleja oli 23aastane ja vanim 59aastane.

\section{Uurimisinstrument}

Ankeet, millega mõõdeti kiusamisliikide esinemissagedust (Kõiv, 2011), koosnes 15 küsimusest, milles kirjeldati agressiivse käitumise liike, toetudes Rayneri ja Hoeli (1997) töökohal kiusamise üldistele (mitte tööga seotud) kategooriatele: oht professionaalsele staatusele (kolm küsimust kiusamisliikidena: avalik alandamine, arvamuste halvustamine, süüdistus seoses jõupingutuste puudumisega), oht personaalsele positsioonile (kuus küsimust kiusamisliikidena: alusetute kuulujuttude levitamine, hirmutamine, karjumine, negatiivsete hüüdnimede andmine, põhjendamatute nõudmiste esitamine, solvamine) ja isolatsioon (kaks küsimust kiusamisliikidena: info varjamine, füüsiline isolatsioon). Füüsilise agressiooni kategooria alla kuulus kolm küsimust (kiusamisliigid: füüsiline rünnak, ähvardamine vägivallaga, ähvardamine positsiooniga) ning küsimustikule lisati küsimus küberkiusamise kohta.

Enesekohase küsimustiku alguses toodi kiusamise definitsioon, lähtudes Olweuse (1999) esitatust, ning instrueeriti uuritavaid küsimustele vastama. Uuritavad pidid end vaatlema kiusamise ohvrina eri suhetes õpilaste ja täiskasvanutega (õpetajad, juhtkond, lapsevanemad ja teised koolitöötajad). Uuritavad vastasid küsimusele „Kui sageli olete kogenud alljärgnevaid juhtumeid oma praeguses töökohas viimase kuue kuu jooksul eri suhetes?“. Vastuseid anti Likerti neljaastmelisel skaalal: „üldse mitte“ (1), „harva“ (2), „sageli“ (3), „väga sageli“ (4). Kiusamise ohvriteks loeti need uuritavad, kes vastasid vähemalt ühele kiusamist puudutavale küsimusele kas „sageli“ või „väga sageli“, sest kiusamisena käsitletakse agressiivset käitumist, mis on oma iseloomult korduv. Ohvrite protsent arvutati koguvalimist.

Küsimustiku reliaabluse väljaselgitamiseks kasutati Cronbachi alfa koefitsienti. Kõigi kiusamiskategooriate skaalade sisemine reliaablus oli usaldusväärne: nelja eelnimetatud kategooria puhul vahemikus $0,77-0,88$. Andmeanalüüsiks kasutati kirjeldavat statistikat ning statistilise olulisuse testidest $\chi^{2}$-testi olulisusnivool 0,05 . 


\section{Tulemused}

Tulemusi käsitledes kirjeldatakse esmalt, kui suur osa õpetajaid ja sotsiaalpedagooge oli üldiselt kogenud õpilaste- ja täiskasvanutepoolset kiusamist, seejärel keskendutakse sellele, mitut liiki kiusamist olid õpetajad ja sotsiaalpedagoogid õpilaste- ja täiskasvanutepoolse kiusamisena kogenud. Järgnevalt pööratakse tähelepanu õpetajate ja sotsiaalpedagoogide ohvrikäitumise levimusele kiusamiskategooriate kaupa. Et kirjeldada ohvrikäitumise olemust detailsemalt, vaadeldakse viimasena kiusamist eri liikide kaupa, mida õpetajad ja sotsiaalpedagoogid olid õpilaste- ja täiskasvanutepoolse kiusamisena kogenud.

Uuringust ilmnes, et õpilastepoolse kiusamise ohvriks oli langenud (kogenud ohvrikäitumist sageli või väga sageli viimase kuue kuu jooksul) 16,9\% $(N=26)$ sotsiaalpedagoogidest ja $35,3 \%(N=200)$ õpetajatest, mis viitab olulistele erinevustele uuritavate vahel $\left(\chi^{2}=17,7, p<0,01\right)$. Enesekohaste hinnangute alusel oli täiskasvanutepoolset (teiste õpetajate, juhtkonna, lapsevanemate, teiste koolitöötajate) kiusamist kogenud 45,5\% $(N=70)$ sotsiaalpedagoogidest ja 25,3\% $(N=143)$ ópetajatest, kusjuures eelnimetatud kahe näitaja vahel ilmnesid statistiliselt olulised erinevused $\left(\chi^{2}=23,5, p<0,00\right)$.

Kõige sagedamini olid õpetajad kogenud õpilastepoolset kiusamist, millele järgnesid lapsevanemate- ja juhtkonnapoolne ning teiste õpetajate poolne kiusamine. Teisi koolitöötajaid nimetasid õpetajad kiusajatena suhteliselt harva. Sotsiaalpedagoogid seevastu olid sagedamini kogenud lapsevanematepoolset kiusamist, sellele järgnesid juhtkonna-, õpilaste- ja õpetajatepoolne ning teiste koolitöötajate poolne kiusamine. Õpetajad ja sotsiaalpedagoogid langesid õpetajate- ja juhtkonnapoolse kiusamise ohvriks suhetes täiskasvanutega 11-17\% juhtudel (olulisi erinevusi ei ilmnenud), kuid nii lapsevanematepoolset kiusamist kui ka teiste koolitöötajate poolset kiusamist olid sotsiaalpedagoogid kogenud oluliselt sagedamini kui õpetajad (vastavalt $\chi^{2}=7,8, p<0,05 ; \chi^{2}=8,6$, $p<0,05)$ (tabel 1).

Tabel 1. Nende õpetajate ja sotsiaalpedagoogide protsent, kes olid viimase kuue kuu jooksul eri suhetes kogenud ohvrikäitumist sageli või väga sageli

\begin{tabular}{|c|c|c|c|c|c|c|c|c|c|c|}
\hline & \multicolumn{2}{|c|}{$\begin{array}{l}\text { Õpilaste- } \\
\text { poolne } \\
\text { kiusamine }\end{array}$} & \multicolumn{2}{|c|}{$\begin{array}{c}\text { Õpetajate- } \\
\text { poolne } \\
\text { kiusamine }\end{array}$} & \multicolumn{2}{|c|}{$\begin{array}{c}\text { Juhtkonna- } \\
\text { poolne } \\
\text { kiusamine }\end{array}$} & \multicolumn{2}{|c|}{$\begin{array}{l}\text { Lapse- } \\
\text { vanemate- } \\
\text { poolne } \\
\text { kiusamine }\end{array}$} & \multicolumn{2}{|c|}{$\begin{array}{c}\text { Teiste } \\
\text { koolitöötajate } \\
\text { poolne } \\
\text { kiusamine }\end{array}$} \\
\hline & $S P$ & ÕP & $S P$ & ÕP & SP & ÕP & $S P$ & ÕP & SP & ÕP \\
\hline $\begin{array}{l}\text { Kiusamist } \\
\text { kogenute } \\
\text { osakaal }\end{array}$ & 16,9 & 35,3 & 15,6 & 11,4 & 17,5 & 12,2 & 22,3 & 12,8 & 9,1 & 1,3 \\
\hline
\end{tabular}

Märkus. ÕP - õpetaja; SP - sotsiaalpedagoog. 
Tabelis 2 toodud andmetest nähtub, et kõigist õpilastepoolset kiusamist kogenud sotsiaalpedagoogidest oli üle $60 \%$ neid, kelle kogemus piirdus ühe kiusamisliigiga, ning kõigist õpetajatest, kes oli kogenud õpilastepoolset kiusamist, oli selline kogemus ligikaudu 40\%-1 (statistiliselt olulised erinevused: $\chi^{2}=22,7$, $p<0,01)$. Vastupidised tendentsid ilmnesid aga kahe kiusamisliigi korral. Nimelt märkis oluliselt rohkem õpetajaid kui sotsiaalpedagooge, et oli kogenud kahte liiki õpilastepoolset kiusamist $\left(\chi^{2}=20,1, p<0,01\right)$. Samuti nähtub tabelist, et ligikaudu neljandik õpilastepoolset kiusamist kogenud sotsiaalpedagoogidest ja õpetajatest oli kokku puutunud vähemalt nelja kiusamisliigiga, kusjuures statistiliselt olulisi erinevusi kahe grupi vahel ei ilmnenud.

Lisaks näitavad uurimistulemused (tabel 2), et üle kolmandiku kuni pool kiusamiskogemusega sotsiaalpedagoogidest ja õpetajatest oli kogenud üht liiki kiusamist, mille korral olid kiusajateks kas teised õpetajad, juhtkond, lapsevanemad või teised koolitöötajad. Õpetajad olid sotsiaalpedagoogidest sagedamini kogenud õpetajatepoolset kiusamist, mis avaldus kahe kiusamisliigina, ja lapsevanematepoolset kiusamist, mis avaldus kolme kiusamisliigina (olulised erinevused vastavalt $\chi^{2}=22,3, p<0,01 ; \chi^{2}=19,6, p<0,01$ ). Sotsiaalpedagoogid seevastu olid kogenud sagedamini kui ópetajad teiste koolitöötajate poolset kiusamist, sh vähemalt nelja liiki kiusamist $\left(\chi^{2}=57,8, p<0,00\right)$.

Tabel 2. Kiusamist kogenud õpetajate ja sotsiaalpedagoogide protsent eri kiusamisliikide korral eri suhetes

\begin{tabular}{|c|c|c|c|c|c|c|c|c|c|c|}
\hline \multirow[t]{2}{*}{$\begin{array}{l}\text { Kiusa- } \\
\text { misliiki- } \\
\text { de arv }\end{array}$} & \multicolumn{2}{|c|}{$\begin{array}{l}\text { Õpilaste- } \\
\text { poolne } \\
\text { kiusamine }\end{array}$} & \multicolumn{2}{|c|}{$\begin{array}{l}\text { Õpetajate- } \\
\text { poolne } \\
\text { kiusamine }\end{array}$} & \multicolumn{2}{|c|}{$\begin{array}{l}\text { Juhtkonna- } \\
\text { poolne } \\
\text { kiusamine }\end{array}$} & \multicolumn{2}{|c|}{$\begin{array}{l}\text { Lapse- } \\
\text { vanemate- } \\
\text { poolne } \\
\text { kiusamine }\end{array}$} & \multicolumn{2}{|c|}{$\begin{array}{c}\text { Teiste } \\
\text { koolitöötajate } \\
\text { poolne } \\
\text { kiusamine }\end{array}$} \\
\hline & SP & ÕP & SP & ÕP & SP & ÕP & SP & ÕP & SP & ÕP \\
\hline 1 & 61,5 & 39,2 & 50,0 & 37,2 & 63,2 & 41,7 & 58,8 & 52,8 & 50,0 & 50,0 \\
\hline 2 & 7,7 & 24,7 & 7,2 & 25,7 & 10,5 & 25,0 & 23,5 & 13,9 & 12,5 & 25,0 \\
\hline 3 & 7,7 & 7,3 & 21,4 & 14,3 & 10,5 & 13,9 & 5,4 & 21,2 & 12,5 & 25,0 \\
\hline $\begin{array}{l}4 \text { ja } \\
\text { rohkem }\end{array}$ & 23,1 & 29,0 & 21,4 & 22,8 & 15,8 & 19,4 & 11,8 & 11,1 & 11,8 & 0,0 \\
\hline
\end{tabular}

Märkus. ÕP - õpetaja; SP - sotsiaalpedagoog.

Võrreldes sotsiaalpedagoogide ja õpetajate ohvrikäitumise levimust nelja kiusamiskategooria (oht professionaalsele staatusele, oht personaalsele positsioonile, isolatsioon, füüsiline agressioon) kaupa (tabel 3), ilmnesid järgmised statistiliselt olulised erinevused: 
1) õpetajad olid sotsiaalpedagoogidest sagedamini kogenud õpilastepoolset kiusamist kahe kiusamiskategooria puhul: oht professionaalsele staatusele $\left(\chi^{2}=19,48, p<0,01\right)$ ja oht personaalsele positsioonile $\left(\chi^{2}=24,44, p<0,01\right)$;

2) õpetajad olid sotsiaalpedagoogidest sagedamini kogenud nii teiste õpetajate poolset kui ka juhtkonnapoolset kiusamist, mis seisnes isolatsioonis (vastavalt $\left.\chi^{2}=8,54, p<0,05 ; \chi^{2}=10,45, p<0,01\right)$;

3) lapsevanematepoolse kiusamise korral olid õpetajad sagedamini kogenud ohtu personaalsele positsioonile $\left(\chi^{2}=19,33, p<0,01\right)$ ning sotsiaalpedagoogid isolatsiooni $\left(\chi^{2}=21,44, p<0,01\right)$;

4) sotsiaalpedagoogid olid õpetajatest sagedamini kogenud teiste koolitöötajate poolse kiusamisena isolatsiooni $\left(\chi^{2}=10,55, p<0,01\right)$.

Füüsilise ohvrikäitumise levimuses kahe uuritavate grupi vahel statistiliselt olulisi erinevusi suhete tasanditel ei ilmnenud.

Tabel 3. Ohvrikäitumist kogenud õpetajate ja sotsiaalpedagoogide protsent kiusamiskategooriate kaupa eri suhetes

\begin{tabular}{|c|c|c|c|c|c|c|c|c|c|c|}
\hline \multirow[t]{2}{*}{$\begin{array}{l}\text { Ohvri- } \\
\text { käitumise } \\
\text { kategooria }\end{array}$} & \multicolumn{2}{|c|}{$\begin{array}{l}\text { Õpilaste- } \\
\text { poolne } \\
\text { kiusamine }\end{array}$} & \multicolumn{2}{|c|}{$\begin{array}{l}\text { Õpetajate- } \\
\text { poolne } \\
\text { kiusamine }\end{array}$} & \multicolumn{2}{|c|}{$\begin{array}{l}\text { Juhtkonna- } \\
\text { poolne } \\
\text { kiusamine }\end{array}$} & \multicolumn{2}{|c|}{$\begin{array}{l}\text { Lapse- } \\
\text { vanemate- } \\
\text { poolne } \\
\text { kiusamine }\end{array}$} & \multicolumn{2}{|c|}{$\begin{array}{c}\text { Teiste } \\
\text { koolitöötajate } \\
\text { poolne } \\
\text { kiusamine }\end{array}$} \\
\hline & $S P$ & ÕP & SP & ÕP & $\mathrm{SP}$ & ÕP & SP & ÕP & SP & ÕP \\
\hline $\begin{array}{l}\text { Oht } \\
\text { professio- } \\
\text { naalsele } \\
\text { staatusele }\end{array}$ & 2,0 & 8,27 & 6,38 & 4,70 & 4,34 & 6,19 & 1,60 & 3,88 & 2,28 & 2,55 \\
\hline $\begin{array}{l}\text { Oht } \\
\text { personaal- } \\
\text { sele posit- } \\
\text { sioonile }\end{array}$ & 2,39 & 10,32 & 4,91 & 4,11 & 2,85 & 3,67 & 0,68 & 4,82 & 1,83 & 1,10 \\
\hline Isolatsioon & 5,19 & 7,09 & 5,02 & 9,71 & 5,18 & 9,68 & 10,96 & 3,93 & 4,45 & 1,34 \\
\hline $\begin{array}{l}\text { Füüsiline } \\
\text { agressioon }\end{array}$ & 1,14 & 2,85 & 1,60 & 1,07 & 1,60 & 2,50 & 0,68 & 1,72 & 1,14 & 0,29 \\
\hline
\end{tabular}

Märkus. ÕP - õpetaja; SP - sotsiaalpedagoog.

Õpetajate ja sotsiaalpedagoogide ohvrikäitumise levimuse võrdlusest ilmneb, et kiusamisliikidest olid õpetajad statistiliselt olulisel määral sagedamini kogenud õpilastepoolse kiusamisena alusetuid kuulujutte, arvamuste halvustamist, hirmutamist, karjumist, negatiivsete hüüdnimedega nimetamist, põhjendamatuid nõudmisi, solvamist ja süüdistusi seoses jõupingutuste puudumisega. Seevastu sotsiaalpedagoogid olid õpilastepoolse kiusamisena sagedamini kogenud küberkiusamist (tabelid 4 ja 5). 
Kahe uuringu valimi ohvrikäitumise levimuse võrdluses ilmnesid järgmised statistiliselt olulised erinevused täiskasvanutepoolse kiusamise liikides:

1) sotsiaalpedagoogid olid õpetajatepoolse kiusamisena kogenud sagedamini süüdistamist seoses jõupingutuste puudumisega ja ähvardamist positsiooniga ning õpetajad olid sagedamini kogenud teiste õpetajate poolse kiusamisena fü̈̈silist isolatsiooni;

2) õpetajad olid sotsiaalpedagoogidest sagedamini kogenud juhtkonnapoolse kiusamisena füüsilist isolatsiooni;

3) lapsevanematepoolse kiusamise sagedasem kogemus, mis seisnes alusetute kuulujuttude levitamises, karjumises ja solvamises, oli sagedasem õpetajatel ning info varjamine sotsiaalpedagoogidel;

4) teiste koolitöötajate poolse kiusamise liikidest olid sotsiaalpedagoogid sagedamini kui õpetajad kokku puutunud info varjamisega (tabelid 4 ja 5).

Tabel 4. Nende õpetajate ja sotsiaalpedagoogide protsent, kes olid viimase kuue kuu jooksul eri suhetes kogenud eri liiki ohvrikäitumist sageli või väga sageli

\begin{tabular}{|c|c|c|c|c|c|c|c|c|c|c|}
\hline \multirow[t]{2}{*}{$\begin{array}{l}\text { Ohvrikäitumise } \\
\text { liik }\end{array}$} & \multicolumn{2}{|c|}{$\begin{array}{l}\text { Õpilaste- } \\
\text { poolne } \\
\text { kiusamine }\end{array}$} & \multicolumn{2}{|c|}{$\begin{array}{l}\text { Õpetajate- } \\
\text { poolne } \\
\text { kiusamine }\end{array}$} & \multicolumn{2}{|c|}{$\begin{array}{l}\text { Juhtkonna- } \\
\text { poolne } \\
\text { kiusamine }\end{array}$} & \multicolumn{2}{|c|}{$\begin{array}{l}\text { Lapse- } \\
\text { vanemate- } \\
\text { poolne } \\
\text { kiusamine }\end{array}$} & \multicolumn{2}{|c|}{$\begin{array}{c}\text { Teiste } \\
\text { koolitöötajate } \\
\text { poolne } \\
\text { kiusamine }\end{array}$} \\
\hline & $\mathrm{SP}$ & ÕP & $\mathrm{SP}$ & ÕP & SP & ÕP & SP & ÕP & SP & ÕP \\
\hline $\begin{array}{l}\text { Alusetud } \\
\text { kuulujutud }\end{array}$ & 2,7 & 12,3 & 6,8 & 6,0 & 1,7 & 4,8 & 0,0 & 7,7 & 2,1 & 1,8 \\
\hline $\begin{array}{l}\text { Arvamuste } \\
\text { halvustamine }\end{array}$ & 2,7 & 9,5 & 11,0 & 7,3 & 4,8 & 7,9 & 1,7 & 4,9 & 2,7 & 1,3 \\
\hline $\begin{array}{l}\text { Avalik } \\
\text { alandamine }\end{array}$ & 2,1 & 6,4 & 3,4 & 3,4 & 2,1 & 5,2 & 1,7 & 3,9 & 2,7 & 2,7 \\
\hline $\begin{array}{l}\text { Füüsiline } \\
\text { isolatsioon }\end{array}$ & 4,1 & 5,8 & 2,7 & 13,2 & 4,1 & 13,0 & 0,0 & 1,3 & 3,4 & 1,3 \\
\hline Füüsiline rünnak & 2,1 & 2,0 & 0,0 & 0,9 & 0,0 & 0,0 & 0,0 & 0,5 & 0,0 & 0,4 \\
\hline Hirmutamine & 1,7 & 7,0 & 1,7 & 2,7 & 3,4 & 4,1 & 0,0 & 3,8 & 1,7 & 0,7 \\
\hline Info varjamine & 10,3 & 15,1 & 8,9 & 9,2 & 7,5 & 10,5 & 22,1 & 6,6 & 5,8 & 1,4 \\
\hline Karjumine & 4,8 & 15,5 & 2,7 & 4,8 & 2,7 & 3,2 & 0,0 & 5,6 & 2,1 & 1,2 \\
\hline Küberkiusamine & 6,2 & 1,6 & 1,7 & 0,5 & 2,7 & 1,3 & 0,0 & 0,9 & 1,7 & 0,0 \\
\hline $\begin{array}{l}\text { Negatiivsed } \\
\text { hüüdnimed }\end{array}$ & 0,7 & 7,0 & 1,7 & 2,5 & 2,7 & 1,8 & 2,1 & 1,6 & 0,0 & 0,4 \\
\hline $\begin{array}{l}\text { Põhjendamatud } \\
\text { nõudmised }\end{array}$ & 2,7 & 9,8 & 1,7 & 4,2 & 1,7 & 4,5 & 1,7 & 3,2 & 2,7 & 1,1 \\
\hline
\end{tabular}




\begin{tabular}{|c|c|c|c|c|c|c|c|c|c|c|}
\hline \multirow[t]{2}{*}{$\begin{array}{l}\text { Ohvrikäitumise } \\
\text { liik }\end{array}$} & \multicolumn{2}{|c|}{$\begin{array}{l}\text { Õpilaste- } \\
\text { poolne } \\
\text { kiusamine }\end{array}$} & \multicolumn{2}{|c|}{$\begin{array}{l}\text { Õpetajate- } \\
\text { poolne } \\
\text { kiusamine }\end{array}$} & \multicolumn{2}{|c|}{$\begin{array}{l}\text { Juhtkonna- } \\
\text { poolne } \\
\text { kiusamine }\end{array}$} & \multicolumn{2}{|c|}{$\begin{array}{l}\text { Lapse- } \\
\text { vanemate- } \\
\text { poolne } \\
\text { kiusamine }\end{array}$} & \multicolumn{2}{|c|}{$\begin{array}{c}\text { Teiste } \\
\text { koolitöötajate } \\
\text { poolne } \\
\text { kiusamine }\end{array}$} \\
\hline & SP & ÕP & SP & ÕP & SP & ÕP & SP & ÕP & SP & ÕP \\
\hline Solvamine & 0,7 & 9,8 & 4,8 & 4,1 & 0,0 & 5,4 & 0,0 & 5,2 & 2,7 & 1,1 \\
\hline $\begin{array}{l}\text { Süüdistamine } \\
\text { seoses } \\
\text { jõupingutuste } \\
\text { puudumisega }\end{array}$ & 1,7 & 8,8 & 8,2 & 3,4 & 6,2 & 5,5 & 2,1 & 4,8 & 1,7 & 2,2 \\
\hline $\begin{array}{l}\text { Ähvardamine } \\
\text { vägivallaga }\end{array}$ & 1,7 & 4,3 & 0,0 & 1,1 & 0,0 & 2,7 & 0,0 & 1,3 & 0,0 & 0,4 \\
\hline $\begin{array}{l}\text { Ähvardamine } \\
\text { positsiooniga }\end{array}$ & 0,0 & 2,3 & 5,0 & 1,3 & 4,8 & 4,8 & 2,1 & 3,4 & 2,7 & 0,2 \\
\hline
\end{tabular}

Märkus. ÕP - õpetaja; SP - sotsiaalpedagoog.

Tabel 5. Õpetajate ja sotsiaalpedagoogide ohvrikäitumise levimuse võrdlus kiusamisliikide kaupa ( $x^{2}$-väärtused)

\begin{tabular}{l|c|c|c|c|c}
\hline $\begin{array}{l}\text { Ohvrikäitumise } \\
\text { liik }\end{array}$ & $\begin{array}{c}\text { Õpilaste- } \\
\text { poolne } \\
\text { kiusamine }\end{array}$ & $\begin{array}{c}\text { Õpetajate- } \\
\text { poolne } \\
\text { kiusamine }\end{array}$ & $\begin{array}{c}\text { Juhtkonna- } \\
\text { poolne } \\
\text { kiusamine }\end{array}$ & $\begin{array}{c}\text { Lapse- } \\
\text { vanemate- } \\
\text { poolne } \\
\text { kiusamine }\end{array}$ & $\begin{array}{c}\text { Teiste } \\
\text { kooli- } \\
\text { töötajate } \\
\text { poolne } \\
\text { kiusamine }\end{array}$ \\
\cline { 2 - 6 } & SP vs. ÕP & SP vs. ÕP & SP vs. ÕP & SP vs. ÕP & SP vs. ÕP \\
\hline $\begin{array}{l}\text { Alusetud } \\
\text { kuulujutud }\end{array}$ & $10,56^{* *}$ & 0,07 & 2,66 & $3,95^{* *}$ & 0,62 \\
\hline $\begin{array}{l}\text { Arvamuste } \\
\text { halvustamine }\end{array}$ & $6,09^{*}$ & 1,67 & 1,15 & 4,49 & 0,41 \\
\hline $\begin{array}{l}\text { Avalik } \\
\text { alandamine }\end{array}$ & 3,62 & 0,05 & 1,90 & 2,15 & 0,17 \\
\hline $\begin{array}{l}\text { Füüsiline } \\
\text { isolatsioon }\end{array}$ & 0,29 & $14,98^{* *}$ & $11,17^{* *}$ & 0,04 & 0,32 \\
\hline Füüsiline rünnak & 0,06 & 0,35 & 0,02 & 0,07 & 0,01 \\
\hline Hirmutamine & $5,58^{*}$ & 0,37 & 0,02 & $5,03^{*}$ & 0,93 \\
\hline Info varjamine & 1,69 & 0,02 & 0,81 & $27,45^{* *}$ & $5,18^{*}$ \\
\hline Karjumine & $6,77^{*}$ & 0,73 & 0,00 & $6,56^{* *}$ & 0,81 \\
\hline Küberkiusamine & $4,13^{*}$ & 0,28 & 0,87 & 0,03 & 0,03 \\
\hline
\end{tabular}




\begin{tabular}{|c|c|c|c|c|c|}
\hline \multirow[t]{2}{*}{$\begin{array}{l}\text { Ohvrikäitumise } \\
\text { liik }\end{array}$} & $\begin{array}{l}\text { Õpilaste- } \\
\text { poolne } \\
\text { kiusamine }\end{array}$ & $\begin{array}{l}\text { Õpetajate- } \\
\text { poolne } \\
\text { kiusamine }\end{array}$ & $\begin{array}{l}\text { Juhtkonna- } \\
\text { poolne } \\
\text { kiusamine }\end{array}$ & $\begin{array}{l}\text { Lapse- } \\
\text { vanemate- } \\
\text { poolne } \\
\text { kiusamine }\end{array}$ & $\begin{array}{c}\text { Teiste } \\
\text { kooli- } \\
\text { töötajate } \\
\text { poolne } \\
\text { kiusamine }\end{array}$ \\
\hline & SP vs. ÕP & SP vs. ÕP & SP vs. ÕP & SP vs. ÕP & SP vs. ÕP \\
\hline $\begin{array}{l}\text { Negatiivsed } \\
\text { hüüdnimed }\end{array}$ & $7,20^{* * *}$ & 0,24 & 0,17 & 0,03 & 0,00 \\
\hline $\begin{array}{l}\text { Põhjendamatud } \\
\text { nõudmised }\end{array}$ & $6,59^{*}$ & 2,42 & 2,90 & 1,54 & 1,47 \\
\hline Solvamine & $11,73^{* *}$ & 0,02 & 4,87 & $5,25^{*}$ & 0,32 \\
\hline $\begin{array}{l}\text { Süüdistamine } \\
\text { seoses } \\
\text { jõupingutuste } \\
\text { puudumisega }\end{array}$ & $8,25^{* *}$ & $5,71^{*}$ & 0,02 & 1,52 & 1,52 \\
\hline $\begin{array}{l}\text { Ähvardamine } \\
\text { vägivallaga }\end{array}$ & 1,98 & 0,55 & 2,78 & 0,03 & 0,03 \\
\hline $\begin{array}{l}\text { Ähvardamine } \\
\text { positsiooniga }\end{array}$ & 2,27 & $5,43^{*}$ & 0,03 & 0,30 & 0,30 \\
\hline
\end{tabular}

Märkus. ${ }^{*} p<0,05 ;{ }^{* *} p<0,01$. ÕP - õpetaja; SP - sotsiaalpedagoog.

\section{Arutelu}

Uuringud on näidanud, et õpetaja on suure riskiga elukutse, kui võtta arvesse laialdast ohvrikäitumise kogemust tööl võrreldes teiste elukutsete esindajatega (Ariza-Montes et al., 2016). Nagu eespool viidatud, on kahe viimase kümnendi jooksul empiirilistes uurimustes suhteliselt palju tähelepanu pööratud õpetajate ühepoolsele kiusamisele koolis (nt õpetajate kiusamine õpilaste poolt), kuid võrdlemisi väheste uurimuste fookuses on olnud õpetajad kui mitmepoolse kiusamise ohvrid. Mõned varasemad haridus- ja sotsiaalvalla uuringud nii õpetajatega kui ka teiste koolitöötajatega (Bradshaw et al., 2013) ning sotsiaaltöötajatega (Koritsas, Coles, \& Boyle, 2010; van Heugten, 2010; Whitaker, 2012) võimaldavad leida lähtekoha uudseks teemaseadeks - käsitleda nii õpetajate kui ka sotsiaalpedagoogide ohvrikogemust laste ja täiskasvanute (õpetajate, juhtkonna, lapsevanemate, teiste töötajate) suhete võrgustikus.

Uurimistulemustest ilmneb, et õpilastepoolse kiusamise ohvriks oli langenud ligi $17 \%$ sotsiaalpedagoogidest ja üle veerandi õpetajatest ning täiskasvanutepoolset kiusamist, kus kiusajateks olid teised õpetajad, juhtkond, lapsevanemad ja teised koolitöötajad, oli kogenud alla poole sotsiaalpeda- 
googidest ja ligi veerand õpetajatest. Praeguse uuringu tulemused sarnanevad teiste rahvusvaheliste uuringute omadega (De Wet, 2006; Dzuka \& Dalbert, 2007; Terry, 1998; Özkiliç, 2012), osutades, et õpilastepoolse kiusamise ohvriks oli langenud umbes veerand kuni pooled õpetajatest ning regulaarselt oli töökiusamist kogenud umbes veerand õpetajatest (De Wet \& Jacobs, 2013; Jennifer et al., 2003; Malinauskienë et al., 2005; Russo et al., 2008).

Praegusest uuringust nähtus, et ohvrikäitumise üldine levimus oli sotsiaalpedagoogide ja õpetajate suhetes õpilaste ja täiskasvanutega erinev: õpetajad olid sagedamini õpilastepoolse ja sotsiaalpedagoogid täiskasvanutepoolse kiusamise ohvrid. Kuigi varem on täheldatud, et õpetajate ja teiste koolitöötajate (nii pedagoogilise kui ka mittepedagoogilise personali) ohvrikäitumise kogemus kaldub olema levimuselt pigem sarnane kui erinev (Bradshaw et al., 2013), ilmnes praegusest uuringust, et kui fookuses on teatud spetsiifilise abistava elukutse esindajate gruppi kuuluva pedagoogilise personali ohvrikäitumise kogemuse levimus, siis võib täheldada erinevusi. Nimelt selgus, et õpetajad olid kogenud kõige sagedamini õpilastepoolset kiusamist, millele järgnesid lapsevanemate-, juhtkonna- ja õpetajatepoolne ning teiste koolitöötajate poolne kiusamine, kusjuures varasematest uuringutest ilmnevad samad tendentsid (Benefield, 2004; Kõiv, 2011; McMahon et al., 2014). Sotsiaalpedagoogid olid aga kogenud eelkõige lapsevanematepoolset kiusamist, millele järgnesid juhtkonna-, õpilaste- ja õpetajatepoolne ning teiste koolitöötajate poolne kiusamine. Sotsiaalpedagoogide seas saadud uurimistulemused sarnanevad varem teiste koolitöötajate hulgas korraldatud uuringu tulemustega (McGuckin \& Lewis, 2008) ning neid võib kõrvutada sotsiaaltöötajate kohta leituga (Whitaker, 2012), millest nähtus, et peamine agressor töökiusamise puhul oli juhtkond.

Võrreldes täiskasvanutepoolse kiusamise levimust kahel uuritavate valimil, ilmnes, et õpetajate- ja juhtkonnapoolse kiusamise kogemus oli umbes kuuendikul sotsiaalpedagoogidest ja õpetajatest, kuid sotsiaalpedagoogid olid sagedamini kui õpetajad kogenud nii lapsevanematepoolset kui ka teiste koolitöötajate poolset kiusamist. Bradshaw jt (2013) on täheldanud samuti, et õpetajate ja teiste koolitöötajate hinnangul esines mõningaid erinevusi täiskasvanutepoolse kiusamise ohvriks langemises - juhtkonna- ja vanematepoolne kiusamine oli võrreldes teiste koolitöötajatega suhteliselt (kuid mitte statistiliselt olulisel määral) ulatuslikum õpetajate seas.

Varasemad uuringud (De Wet \& Jacobs, 2013; Riley et al., 2011) on näidanud, et kolmandik õpetajatest oli kiusamise ohvrina kogenud mitut liiki töökiusamist. Ka praeguse uuringu tulemused osutasid mitmele suhete tasandile koolis, kus variatiivne kiusamine võib aset leida: nimelt oli õpetajatel suurem 
ohvrikogemus (sh kiusamisliikide võrdluses) õpilaste, õpetajate ja lapsevanematega, kuid sotsiaalpedagoogidel koolitöötajatega.

Siinses uurimuses püstitati hüpotees, et ópetajatel on õpilaste- ja lapsevanematepoolne kiusamine, mille korral verbaalselt ohustatakse personaalset positsiooni, ulatuslikum kui sotsiaalpedagoogidel. Hüpotees leidis kinnitust ja täpsustus. Uuringu tulemusena selgus, et õpilaste- ja lapsevanematepoolne kiusamine, mis avaldus ohuna personaalsele positsioonile nii verbaalsete kui ka kaudsete ohvrikäitumise liikide korral (nt alusetud kuulujutud, hirmutamine, karjumine, negatiivsed hüüdnimed, põhjendamatud nõudmised, solvamine), oli õpetajatel sagedasem kui sotsiaalpedagoogidel. Lisaks ilmnes, et õpilastepoolne kiusamine ohuna professionaalsele staatusele (nt arvamuste halvustamine, süüdistamine seoses jõupingutuste puudumisega) oli õpetajatel sagedasem kui sotsiaalpedagoogidel. Ka õpetajate ja teiste koolitöötajate küsitluse andmetest (Bradshaw et al., 2013) on selgunud, et õpetajad olid võrreldes teiste koolitöötajatega kogenud sagedamini verbaalset ja suhetega seotud kaudset kiusamist.

Uurimistulemused näitavad ka seda, et täiskasvanutepoolse kiusamise kogemus seoses isolatsiooniga eri suhetes kaldus sotsiaalpedagoogidel ja õpetajatel olema erinev. Nimelt olid õpetajad kogenud sagedamini füüsilist isolatsiooni teiste õpetajate poolse ja juhtkonnapoolse kiusamisena ning sotsiaalpedagoogid info varjamist teiste koolitöötajate poolse ja lapsevanematepoolse kiusamisena, kusjuures viimasena nimetatud ohvrikäitumise liik oli suhteliselt prevaleeriv täiskasvanutepoolse kiusamisena kõigis suhetes. Varasemad uuringud on näidanud samu tendentse: nii juhtkonnapoolne (Blasé et al., 2008) kui ka teiste täiskasvanute poolne (Cemaloğlu, 2007; De Wet \& Jacobs, 2013; NASUWT, 2012) töökiusamine väljendub ülekaalukalt ignoreerimise kui passiivse kiusamiskäitumise vormidena. Ka sotsiaaltöötajad on täheldanud ignoreerimise kui töökiusamise suurt kaalu teiste kiusamisliikide seas (Whitaker, 2012).

Võrreldes sotsiaalpedagoogide ja õpetajate ohvrikäitumise olemust liikide kaupa, võib uurimistulemusele toetudes välja tuua kolm tendentsi: 1) lapsevanematepoolne kiusamine ohuna õpetajate personaalsele staatusele (nt alusetud kuulujutud, karjumine, solvamine) oli ülekaalukam õpetajatel; 2) õpetajatepoolne tõsist laadi kiusamine (nt süüdistamine, ähvardamine positsiooniga) oli sagedasem sotsiaalpedagoogidel ning 3) õpilastepoolne küberkiusamine oli ülekaalukam sotsiaalpedagoogide seas. Varasemates uurimustes on käsitletud õpetajate küberkiusamise kogemust kiusamisena töökohal (McMahon et al., 2014), õpilastepoolse kiusamisena (Kauppi \& Pörhölä, 2012) või ka teiste koolitöötajate ohvrikäitumise kogemusena (Bradshaw et al., 2013). Seega, õpetajad kaldusid olema täiskasvanutepoolse passiivse kiusamise ohvrid, mis 
avaldus eelkõige teiste õpetajate ja juhtkonnapoolse kiusamisena, täpsemalt füüsilise isolatsioonina. Sotsiaalpedagoogide täiskasvanutepoolne kiusamine oli samuti eelkõige passiivne, kuid avaldus ülekaalukalt lapsevanematepoolse ja teiste koolitöötajate poolse kiusamisena - info varjamisena. Õpetajad olid kogenud lapsevanematepoolset otsest ja kaudset verbaalset kiusamist, mis oli personaalset laadi, ning sotsiaalpedagoogid õpetajatepoolset verbaalset tõsist ja otsest kiusamist, mis seisnes süüdistustes ja ohus professionaalsele staatusele. Õpilastepoolne õpetajate kiusamine oli ülekaalukalt verbaalne personaalset ja professionaalset laadi otsene agressioon. Seevastu sotsiaalpedagooge kiusasid õpilased eelkõige meediavahendite vahendusel.

Praegusel uurimusel on mõned piirangud. Esiteks, andmete kogumine enesekohase meetodiga sisaldab mõningaid sisemisi piiranguid, sest tegu on sotsiaalselt tundliku teemaga, kus meenutamise korrektsus võib kallutada tulemusi. Teisalt, uuritavate osalus (üle 50\%) oli küll aktsepteeritav, kuid võib sotsiaalselt tundliku teema käsitlemisel viidata vildakale valimile. Edaspidi samas valdkonnas uuringuid planeerides võiks keskenduda eri kooliastmetel õpetavate (nt lapsed või noorukid) ja eri tööstaažiga õpetajate ohvrikogemuse uurimisele, samuti võiks valimit laienda, et võrrelda ka teiste abistavate elukutsete esindajate (nt psühholoogide, eripedagoogide) ohvrikogemust kooli kontekstis.

Eelnimetatud kitsaskohtadest hoolimata on uurimistulemused aktuaalsed, näidates, et mitte ainult õpetajad, vaid ka sotsiaalpedagoogid võivad olla kiusajate märklauaks eri suhete tasanditel ning kannatada mitte ainult õpilaste-, vaid ka täiskasvanutepoolse kiusamise all. See viitab vajadusele luua mõlema professiooni esindajate tarbeks juurde nii koolisiseseid kui ka -väliseid mentorlusega seotud toetussüsteeme. Abistavate elukutsete esindajad, nagu sotsiaalpedagoogid, puutuvad paratamatult oma töös kokku klientidega, kellel on probleeme (ka vägivallaga), mistõttu võivad nad sattuda kiusamise ohvriks. Seega, kiusamisalane ennetus- ja sekkumistegevus ei peaks haarama mitte ainult kooli, vaid ka kogukonna tasandit, tugevdades koostööd eri institutsioonide vahel. Teisalt, ohvrikäitumise varjatud olemus, iseäranis täiskasvanute suhetes, viitab suuremale vajadusele tugevdada mitut suhete tasandit hõlmavat töökiusamise ennetus- ja sekkumistegevust, et parandada eelkõige kooli sotsiaalpsühholoogilist kliimat.

\section{Kasutatud kirjandus}

Ariza-Montes, A., Muniz, R. N. M., Leal-Rodríquez, A. L., \& Leal-Millán, A. G. (2016). Workplace bullying among teachers: An analysis from the job demandsresources (JD-R) model perspective. Journal of Occupational and Environmental Medicine, 58(8), 818-827. https://doi.org/10.1097/JOM.0000000000000804 
Benefield, J. (2004). Teachers - the new targets of schoolyard bullies? Paper to NZARE Conference, November. Wellington: PPTA.

Blasé, J., Blasé, J., \& Du, F. (2008). The mistreated teacher: A national study. Journal of Educational Administration, 46(3), 263-301. https://doi.org/10.1108/09578230810869257

Bradshaw, C. P., Waasdorp, T. E., O’Brennan, L. M., \& Gulemetova, M. (2013). Teachers' and education support professionals' perspectives on bullying and prevention: Findings from a National Education Association Study. School Psychology Review, 42(3), 280-297.

Cemaloğlu, N. (2007). The exposure of primary school teachers to bullying: An analysis of various variables. Social Behavior and Personality, 35(6), 789-802. https://doi.org/10.2224/sbp.2007.35.6.789

Coyne, I. (2011). Bullying in the workplace. In C. P. Monks \& I. Coyne (Eds.), Bullying in different context (pp. 157-184). Cambridge: Cambridge University Press. https://doi.org/10.1017/CBO9780511921018.008

Delfabbro, P., Winefield, T., Trainor, S., Dollard, M., Anderson, S., Metzer, J., \& Hammarstrom, A. (2006). Peer and teacher bullying/victimization of South Australian secondary school students: Prevalence and psychosocial profiles. British Journal of Educational Psychology, 76(1), 71-90. https://doi.org/10.1348/000709904X24645

De Wet, C. (2006). Free State educators' experiences and recognition of bullying at schools. South African Journal of Education, 26(1), 61-73.

De Wet, C. (2010a). The reasons for and the impact of principal-on-teacher bullying on the victims' private and professional lives. Teaching and Teacher Education, 26(7), 1450-1459. https://doi.org/10.1016/j.tate.2010.05.005

De Wet, C. (2010b). Victims of educator-targeted bullying: A qualitative study. South African Journal of Education, 30, 189-201.

De Wet, C. (2011). The professional lives of teacher victims of workplace bullying: A narrative analysis. Perspectives in Education, 29(4), 66-77.

De Wet, C. (2012). Risk factors for educator-targeted bullying: A social-ecological perspective. Journal of Psychology in Africa, 22(2), 239-244.

De Wet, C., \& Jacobs, L. (2013). South African teachers' exposure to workplace bullying. The Journal for Transdisciplinary Research in Southern Africa, 9(3), 446-464. https://doi.org/10.4102/td.v9i3.190

Dzuka, J., \& Dalbert, C. (2007). Student violence against teachers: Teachers' wellbeing and the belief in a just world. European Psychologist, 12(4), 253-260. https://doi.org/10.1027/1016-9040.12.4.253

Edelmann, R. J., \& Woodall, L. (1997). Bullying at work. Occupational Psychologist, $32,28-31$.

James, D. J., Lawlor, M., Courtney, P., Flynn, A., Henry, B., \& Murphy, N. (2008). Bullying behaviour in secondary schools: What roles do teachers play? Child Abuse Review, 17(3), 160-173. https://doi.org/10.1002/car.1025

Jennifer, D., Cowie, H., \& Ananiadou, K. (2003). Perceptions and experience of workplace bullying in five different working populations. Aggressive Behavior, 29(6), 489-496. https://doi.org/10.1002/ab.10055 
Kauppi, T., \& Pörhölä, M. (2012). School teachers bullied by their students: Teachers' attributions and how they share their experiences. Teaching and Teacher Education, 28(7), 1059-1068. https://doi.org/10.1016/j.tate.2012.05.009

Khoury-Kassabri, M., Astor, R. A., \& Benbenishty, R. (2009). Middle Eastern adolescents' perpetration of school violence against peers and teachers: A cross-cultural and ecological analysis. Journal of Interpersonal Violence, 24(1), 159-182. https://doi.org/10.1177/0886260508315777

Koritsas, S., Coles, J., \& Boyle, M. (2010). Workplace violence towards social workers: The Australian experience. British Journal of Social Work, 40(1), 257-271. https://doi.org/10.1093/bjsw/bcn134

Kõiv, K. (2009). Bullying among Estonian pupils: An overview. In J. Mikk, M. Veisson, \& P. Luik (Eds.), Teenagers in Estonia: Values and behaviour. Estonian studies in education (Vol. 1, pp. 103-123). Frankfurt am Main etc.: Peter Lang.

Kõiv, K. (2011). Bullying in a school context: Teachers as victims. Psicologia e Educação, IX-X(1, 2), 95-106.

Kõiv, K. (2015). Changes over a ten-year interval in the prevalence of teacher targeted bullying. Procedia - Social and Behavioral Sciences, 171, 126-133. https://doi.org/10.1016/j.sbspro.2015.01.098

Malinauskienë, V., Obelenis, V., \& Đopagienë, D. (2005). Psychological terror at work and cardiovascular diseases among teachers. Acta Medica Lituanica, 12(2), 20-25.

McGuckin, C., \& Lewis, C. A. (2008). Management of bullying in Northern Ireland schools: A pre-legislative survey. Educational Research, 50(1), 9-23. https://doi.org/10.1080/00131880801920361

McMahon, S. D., Martinez, A., Espelage, D., Rose, C., Reddy, L. A., Lane, K., ... Brown, V. (2014). Violence directed against teachers: Results from a national survey. Psychology in the Schools, 51(7), 753-766. https://doi.org/10.1002/pits.21777

Monks, C. P., \& Coyne, I. (Eds.) (2011). Bullying in different context. Cambridge: Cambridge University Press.

Monks, C. P., Smith, P. K., Naylor, P., Barter, C., Ireland, J. L., \& Cyne, I. (2009). Bullying in different contexts: Commonalities, differences and the role of theory. Aggression and Violent Behavior, 14(2), 146-156.

https://doi.org/10.1016/j.avb.2009.01.004

NASUWT (2012). Workplace bullying in schools and colleges. Birmingham: NASUWT.

Olweus, D. (1999). Sweden. In P. K. Smith, Y. Morita, J. Junger-Tas, D. Olweus, R. Catalano, \& P. Slee (Eds.), The nature of school bullying: A cross-national perspective (pp. 7-27). London: Routledge.

Parsons, L. (2005). Bullied teacher, bullied student: How to recognize the bullying culture in your school and what to do about it. Canada: Pembroke Publishers.

Pervin, K., \& Turner, A. (1998). A study of bullying of teachers by pupils in an inner London school. Pastoral Care in Education, 16(4), 4-10. https://doi.org/10.1111/1468-0122.00104

Pyhältö, K., Pietarinen, J., \& Soini, T. (2015). When teaching gets tough - Professional community inhibitors of teacher-targeted bullying and turnover intentions. Improving Schools, 18(3), 263-276. https://doi.org/10.1177/1365480215589663

Rayner, C., \& Hoel, H. (1997). A summary review of literature relating to workplace bullying. Journal of Community and Applied Social Psychology, 7(3), 181-191. https://doi.org/10.1002/(SICI)1099-1298(199706)7:3<181::AID-CASP416>3.0.CO;2-Y 
Rayner, C., \& Keashly, L. (2005). Bullying at work: A perspective from Britain and North America. In S. Fox \& P. E. Spector (Eds.), Counterproductive work behavior: Investigations of actors and targets (pp. 271-296). Washington: American Psychological Association. https://doi.org/10.1037/10893-011

Riley, D., Duncan, D. J., \& Edwards, J. (2011). Staff bullying in Australian schools. Journal of Educational Administration, 49(1), 7-30. https://doi.org/10.1108/09578231111102036

Russo, A., Milić, R., Knežević, B., Mulić, R., \& Mustajbegović, J. (2008). Harassment in workplace among school teachers: Development of a survey. Croatian Medical Journal, 49(4), 545-552. https://doi.org/10.3325/cmj.2008.4.545

Smith, P. K. (2011). Bullying in schools: Thirty years of research. In C. P. Monks \& I. Coyne (Eds.), Bullying in different context (pp. 36-60). Cambridge: Cambridge University Press. https://doi.org/10.1017/CBO9780511921018.003

Smith, P. K., Morita, Y., Junger-Tas, J., Olweus, D., Catalano, R., \& Slee, P. (Eds.) (1999). The nature of school bullying: A cross-national perspective. London, New York: Routledge.

Terry, A. A. (1998). Teachers as targets of bullying by their pupils: A study to investigate incidence. British Journal of Educational Psychology, 68(2), 255-268. https://doi.org/10.1111/j.2044-8279.1998.tb01288.x

Twemlow, S. W., \& Fonagy, P. (2005). The prevalence of teachers who bully students in schools with differing levels of behavioral problems. American Journal of Psychiatry, 162(12), 2387-2389. https://doi.org/10.1176/appi.ajp.162.12.2387

Van Heugten, K. (2010). Bullying of social workers: Outcomes of a grounded study into impacts and interventions. The British Journal of Social Work, 40(2), 638655. https://doi.org/10.1093/bjsw/bcp003

Whitaker, T. (2012). Social workers and workplace bullying: Perceptions, responses and implications. Work, 42(1), 115-123. https://doi.org/10.3233/WOR-2012-1335

Whitted, K. S., \& Dupper, D. R. (2008). Do teachers bully students? Findings from a survey of students in an alternative education setting. Education and Urban Society, 40(3), 329-341. https://doi.org/10.1177/0013124507304487

Özkiliç, R. (2012). Bullying toward teachers: An example from Turkey. Eurasian Journal of Educational Research, 47, 95-112. 


\title{
Teachers and social pedagogues as victims of bullying
}

\author{
Kristi Kõiv ${ }^{\mathbf{a}^{1}}$ \\ ${ }^{a}$ Institute of Education, University of Tartu
}

\section{Summary}

\section{Introduction}

Most studies of school (Smith, 2011) and workplace (Coyne, 2011) bullying define bullying by means of three criteria: bullying is when someone directs aggressive behaviour towards another or intentionally hurts and harms a target person; bullying occurs repeatedly over a lengthy period of time; and there exists an imbalance of power with the person being subjected to bullying who cannot defend him or herself.

Workplace bullying in schools overwhelms complex dynamics (Parsons, 2005): on one side, teachers may be bullied by other teachers, students, staff, principals, parents; and on the other side, teachers may bully other teachers, staff, principals, parents and students.

Bullying against teachers in the workplace is an issue of international studies providing evidence about its nature and prevalence all around the world (e.g. Benefield, 2004; Cemaloğlu, 2007; De Wet \& Jacobs, 2013; Jennifer et al., 2003; Kõiv, 2011; Malinauskienë et al., 2005; McMahon et al., 2014; NASUWT, 2012; Pyhältö et al., 2015). Despite differences in victimization rates of teachers bullying due to methodological differences between studies, the workplace bullying among teachers is a problem which is quite widespread, but has received relatively little attention to teachers as multiple targeted victims in the school settings (e.g. Benefield, 2004; Kõiv, 2011; McGuckin \& Lewis, 2008; Riley et al., 2011; NASUWT, 2012) compared with teacher-targeted bullying from pupils (e.g. De Wet, 2006; Dzuka \& Dalbert, 2007; James et al., 2008; Kauppi \& Pörhölä, 2012; Khoury-Kassabri et al., 2009; Kõiv, 2011; Pervin \& Turner, 1998; Terry, 1998).

The teacher-target bullying from students, parents, staff, and principals is a cross-bordered problem in schools, whereby the assessment of this problem mostly focuses on victimization by students compared with other school staff members' (e.g. non-teaching and education support professionals) victimization experiences generated by other perpetrators in the workplace (Bradshaw 
et al., 2013) and also among social workers (Koritsas et al., 2010; van Heugten, 2010; Whitaker, 2012).

These challenges suggest that there is a need to gather data from teachers' and social pedagogues' self-reports about their experiences of victimization based on multiple perpetrators (children and adults), and assess the prevalence of various types and categories of victimization. The following to two key research questions were formulated:

1. What is the extent of different types of bullying experienced by teachers and social pedagogues in teacher-pupil, teacher-teacher, teacher-school administrative staff, teacher-school maintenance staff, and teacher-parent relationships?

2. What is the extent of different bullying categories (threat to professional status, threat to personal standing, isolation, and physical aggression) experienced by teachers in teacher-pupil, teacher-teacher, teacher-school administrative staff, teacher-school maintenance staff, and teacher-parent relationships?

The aim of the study was to compare the extent and nature of bullying experienced by teachers and social pedagogues in teacher-pupil, teacher-teacher, teacher-school administrative staff, teacher-school maintenance staff, and teacher-parent relationships in Estonian schools.

It was hypothesized that victimization of teachers by pupils and parents in the area of verbal threat to personal standing would involve a greater proportion than the victimization of social pedagogues.

\section{Study design and selection of subject}

In 2016 a cross-sectional survey consisting of two nationwide separate samples - teachers and social pedagogues, was conducted in Estonia. A systematic random sampling was used to select two schools from all separate districts, whereby the ratio of different types of schools (basic schools versus gymnasium) among sample of schools corresponded to the countrywide school sample. All teachers from randomly selected schools were included in the research sample and personal e-questionnaires were sent by the author. Participant rate was $54.7 \%$. The first sample consisted of 567 teachers: 502 females $(88.5 \%)$ and 65 males (11.5\%). The average age of the subjects was 46.29 years $(S D=11.7)$. The youngest subject was 20 years old and the oldest was 71 .

Personal e-questionnaires were sent by the author to all social pedagogues working in Estonia at different institutions (mostly at schools). Participant rate was $58.8 \%$. The second sample consisted of 153 social pedagogues: 147 females (95.4\%) and 7 males (4.6\%). The average age of the respondents was 41.3 years $(S D=8.5)$. The youngest subject was 23 years old and the oldest was 59 . 


\section{Instrument}

A self-report instrument for the measurement of prevalence of different types of bullying of teachers by students and by adults (other teachers, administration parents and maintenance staff) in school context was used (Kõiv, 2011) consisting of 15 items which described acts of harming or hurting the target person. The bullying-type experiences based on categorization of general workplace bullying (Rayner \& Hoel, 1997) including: (1) threat to professional status: accusation regarding lack of effort, belittling opinion, public humiliation; (2) threat to personal standing: devaluation, insults, intimidation, namecalling, offensive remarks, shouting, slandering; (3) isolation: physical isolation, withholding of information. Physical aggressive behaviour as a category of bullying was also included and one item regarding cyberbullying was added to the instrument. Participants indicated how often they had been bullied at school during the last six months using a 4-point Likert scale (never, often, very often) after a definition of bullying by following the pattern established by Olweus (1999). A person was considered a victim when he/she reported being bullied "often" or "very often" at least one out of a list of bullying items.

\section{Results}

This article reports on the results from a cross-sectional study of Estonian teachers' and social pedagogues' victimization by students and adults (other teachers, students, staff, principals, parents) from three areas of study: general prevalence of victimization of teachers and social pedagogues viewing them as targets of children and adult bullying in schools; how commonly four broad categories of victimization from bullying were experienced by the two samples of respondents in different types of relationships in school; and thirdly, we will focus on specific acts, listed under each of the four types or categories (included also cyberbullying) of victimization among teachers and social pedagogues. The results were subjected to descriptive statistical analysis and Chi-square test for comparison of frequencies and are discussed with reference to other studies.

This study exposes the commonness of victimization among participating teachers and social pedagogues and showed that $35 \%$ of teachers and $17 \%$ of social pedagogues were victims of students bullying, and $25 \%$ of teachers and $46 \%$ of social pedagogues were victims of adult bullying.

Research results indicated that more teachers were victimized at colleagueon-teacher level and more social pedagogues were victimized at adult-on-adult level, whereby it was found that social pedagogues were more victimized by parents and other school staff members. 
Consistently, by far the most bullying reported by teachers was from students, followed by parents, management, other teachers and then, to a far lesser extent, from other staff members at school. For social pedagogues, the most frequent perpetrators of bullying were parents, then principals, followed by students, teachers, and to a lesser degree other staff members at school.

The analysis of the categories of teachers' and social pedagogues' victimization rates in different relationship levels indicated that teachers as victims of bullying experienced a significantly greater threat to personal standing and to professional status in the interpersonal relationships with pupils and with parents compared with social pedagogues.

Teachers' and social pedagogues' victimization forms were examined across the five perpetrator categories (student, parent, other teachers, administrative staff and school maintenance staff) and it was revealed that verbal direct and indirect forms of victimization (e.g. accusation regarding lack of effort, slandering, intimidation, shouting, name-calling, belittling opinion) in teacherstudent and teacher-parent relationships tended to be more prevalent among teachers compared with social pedagogues.

Thus, the hypothesis that victimization of teachers by pupils and parents in the area of verbal threat to personal standing would involve a greater proportion than victimization of social pedagogues was confirmed.

Different types of isolation (physical isolation, withholding of information) were relatively prevalent across five perpetrator categories (student, parent, other teachers, administrative staff and school maintenance staff) among two study group members, whereby social pedagogues' victimization experiences were more frequently connected with withholding of information in relationships with parents and other school staff members; and teachers were more frequently victims of other teachers and administrative staff aggression in the area of physical isolation. Additionally, it was revealed that more social pedagogues than teachers reported being victimized by students in the area of cyberbullying.

Results indicated that not only teachers, but also social pedagogues, were victimized by multiple individuals within the school ecology.

Keywords: bullying, prevalence of victimization, teacher, social pedagogue, Estonia 